\title{
Visual Stimulation Regulates the Expression of Transcription Factors and Modulates the Composition of AP-1 in Visual Cortex ${ }^{a}$
}

\author{
Bozena Kaminska, ${ }^{1,2}$ Leszek Kaczmarek, ${ }^{1,2}$ and Avi Chaudhuri ${ }^{1}$ \\ 1Department of Psychology, McGill University, Montréal, Québec, Canada H3A 1B1, and 2Nencki Inslitute, \\ Warsaw, Poland 02093
}

It is believed that long-term changes in neuronal function are orchestrated by transcription factors, such as AP-1 and ZIF 268 , which are in turn regulated by synaptic stimulation. To further our understanding of the functional effects of such expression, we have examined the DNA-binding activities of both AP-1 and ZIF 268 by way of electrophoretic mobility shift assays (EMSA) on nuclear extracts from visual cortices of rats treated with selective light exposure. Visual stimulation after dark rearing increased the DNA-binding activities of both AP-1 and ZIF 268 to their highest levels within $2 \mathrm{hr}$. ZIF 268 thereafter dropped to levels similar to that observed in naive animals, whereas AP-1 DNA-binding activity continued to remain elevated even after $24 \mathrm{hr}$ of stimulation. The components of the AP-1 complex, when assessed by EMSA-supershift analysis,

It is now well established that prolonged alteration of sensory stimulation initiates a set of anatomical and physiological changes in the CNS that ultimately leads to the brain's ability to effectively adapt to the modified stimulus (Merzenich and Sameshima, 1993; O'Leary et al., 1994). The levels of various neurotrophins, neurotransmitter/receptor systems, structural proteins, and intracellular second messengers are modulated by synaptic stimulation (Hendry and Kennedy, 1986; Castren et al., 1992; Benson et al., 1994). It is believed that these are either affected by or ultimately converge on the third-messenger systems (Kaczmarek and Kaminska, 1989; Morgan and Curran, 1991). The discovery that neuronal activation can induce the expression of a large number of genes-many of which code for transcription factors such as AP-1 and ZIF 268 - has focused attention on their role in regulating long-term changes in brain function (Morgan and Curran, 1991; Kaczmarek, 1993a,b).

The molecular composition of the AP-1 complex is heterogeneous. Both the Fos (c-Fos, FosB, Fra-1, Fra-2) and Jun (c-Jun, JunB, JunD) families of nuclear phosphoproteins may participate in forming a homo- or heterodimeric complex that binds to an AP-1 consensus sequence that is present in numerous promoters

Received March 20, 1996; accepted April 3, 1996.

This work was supported by research grants from the Medical Research Council of Canada (MRC) and the Natural Sciences and Engineering Research Council of Canada (NSERC) to A.C. L.K. was supported by Visiting Research Fellowships from NSERC and FRSQ. A.C. is an MRC Scholar and Alfred P. Sloan Research Fellow.

Correspondence should be addressed to Avi Chaudhuri, Department of Psychology, McGill University, 1205 Penficld Avenue, Montréal, Québcc, Canada H3A 1 B1.

"In adherence to the usual convention, specific genes such as c-fos or zif 268 are designated by italics, and the proteins encoded by the genes (in this case, c-Fos and Zif 268) are written in roman type with one capital letter; DNA-binding activities of the transcription factors (AP-I, ZIF 268) are presented in the upper case.

Copyright (C) 1996 Society for Neuroscience $0270-6474 / 96 / 163968-11 \$ 05.00 / 0$ showed considerable variability under different conditions of exposure. FosB and JunD were the major constituents of AP-1 in both naive and dark-reared animals. Brief visual stimulation ( $2 \mathrm{hr}$ ) added c-Fos, c-Jun, and JunB to this complex, whereas prolonged stimulation $(6-24 \mathrm{hr})$ reduced c-Fos and c-Jun levels significantly, leaving only FosB, JunB, and JunD as the major components of AP-1. These results suggest that transcriptional control by AP-1 may be generated by selective combinatorial interactions of different members of the Fos and Jun families and that are guided by activity-dependent processes.

Key words: Fos; Zif 268; immediate-early gene; gel-shift immunocytochemistry; dark rearing; superior colliculus

(Morgan and Curran, 1991). After binding, the AP-1 may either activate or repress the candidate gene (Angel and Karin, 1991; Kobierski et al., 1991). It has been shown recently that the composition of the AP-1 complex is different in various physiological situations and that even closely related members of the same family may contribute to quite distinct biological phenomena (Hope et al., 1994; Kaminska et al., 1994; Kasof et al., 1995).

We have learned much about AP-1 induction in the visual system from developmental studies. McCormack et al. (1992) have found that $c$-fos, $c$-jun, junB, and zif 268 expression rose sharply in cat visual cortex at the onset of the critical period and decreased afterward, suggesting that they may play an important role in activity-guided changes in the developing nervous system. Further evidence for a linkage with activity is based on studies that show elevated levels of $c$-fos, junB, and zif $268 \mathrm{mRNA}$ in the visual cortex after selective light stimulation (Worley et al., 1990; Rosen et al., 1992; Chaudhuri et al., 1995b). However, with the exception of the $c$-fos gene (Beaver et al., 1993; Mower, 1994), there is no evidence that the mRNA of AP-1 components are translated into proteins. This is not a trivial point because it has been shown that increased transcription of these genes may not necessarily be accompanied by translation into proteins under some conditions (Kiessling et al., 1993; Worley et al., 1993). Furthemore, it is known that certain AP-1 components may be expressed in the absence of a dimeric partner (Leah et al., 1993) and that other proteins, such as Maf, may be engaged to produce AP-1 activity (Kerppola and Curran, 1995; Morgan and Curran, 1995).

Given these issues, it is necessary to proceed beyond documenting the mere presence of mRNAs and proteins of the various AP-1 members and determine whether a functional AP-1 complex is present in the nucleus. To accomplish this, we have examined 
AP-1 DNA-binding activity using electrophoretic mobility shift assay (EMSA) of nuclear proteins obtained from the visual cortices of rats under various conditions of light stimulation.

\section{MATERIALS AND METHODS}

Animals and rearing conditions. The data reported in this paper were obtained from a total 35 male Long-Evans hooded rats (Charles River, Wilmington, MA). All animals were -3 months old and had a minimum weight of $175 \mathrm{gm}$. For the EMSA experiments, a total of 18 rats were reared in darkness for $7 \mathrm{~d}$, of which 13 were then exposed to light for periods of $45 \mathrm{~min}$ or 2,6 , or $24 \mathrm{hr}$. Eleven rats were used for various control conditions. Animals for each set of experiments were exposed to the same set of environmental conditions and were always kept in pairs to reduce social isolation.

To visualize the spatial distribution of c-Fos and Zif 268 proteins in rat visual cortex, we performed immunostaining procedures on animals that were exposed to brief periods of light after dark rearing. A total of 6 rats was used and divided into three groups of two each. All animals were monocularly enucleated under sodium pentobarbital anesthesia and allowed to recover. Two animals were kept under normal light/dark cycle for $8 \mathrm{~d}$. The other four were placed in complete darkness for $6 \mathrm{~d}$. Of these, two were processed immediately for brain collection without any light exposure, whereas the second set was exposed to light for $2 \mathrm{hr}$ before killing.

Preparation of protein extracts and analysis of DNA-binding activities. Brain tissue from the occipital region of all rats was obtained for this experiment and immediately processed for nuclear protein extraction (Kaminska and Kaczmarek, 1993; Kaminska et al., 1994). The tissue was manually pulverized with a Teflon pestle and suspended in $0.5 \mathrm{ml}$ of buffer A (10 mм HEPES, pH 7.9, $1.5 \mathrm{~mm} \mathrm{MgCl}_{2}, 10 \mathrm{~mm} \mathrm{KCl}, 1 \mathrm{~mm}$ DTT, and the protease inhibitors $1 \mathrm{mM} P M S F, 10 \mathrm{mg} / \mathrm{ml}$ aprotinin, $10 \mathrm{mg} / \mathrm{ml}$ leupeptin, and $1 \mathrm{mg} / \mathrm{ml}$ pepstatin A) (all products from Sigma, St. Louis, MO). After incubation for $15 \mathrm{~min}$ on ice, Nonidet NP40 was added to make a final concentration of $1 \%$ before centrifugation at $12,000 \mathrm{rpm}$ for $1 \mathrm{~min}$ at $4^{\circ} \mathrm{C}$. The crude pellet was resuspended in buffer $\mathrm{B}(20 \mathrm{mM}$ HEPES, $0.84 \mathrm{M} \mathrm{NaCl}, 1.5 \mathrm{mM} \mathrm{MgCl} 2,0.4 \mathrm{~mm}$ EDTA, $1 \mathrm{~mm} \mathrm{DTT}, 25 \% \mathrm{v} / \mathrm{v}$ glycerol, and protease inhibitors as above) and incubated for $15 \mathrm{~min}$ at $4^{\circ} \mathrm{C}$. After centrifugation for $15 \mathrm{~min}$ at $12,000 \mathrm{rpm}$, the supernatant was removed and stored at $-70^{\circ} \mathrm{C}$. The protein content was estimated by the Bradford method and verified by Coomassie staining of SDS-PAGE gels (NOVEX pre-cast 12\% Tris-glycine gels; Novex, San Diego, CA).

We have applied the electrophoretic mobility shift assay (EMSA) technique to assess the DNA-binding activities of the extracted nuclear proteins from the different experimental conditions. Twenty micrograms of nuclear protein were preincubated for $10 \mathrm{~min}$ at room temperature in binding buffer [ $10 \mathrm{~mm}$ HEPES, $25 \mathrm{mM} \mathrm{KCl}, 0.5 \mathrm{~mm}$ EDTA, $0.25 \mu \mathrm{g} / \mathrm{ml}$ bovine serum albumin, $1 \mathrm{~mm} \mathrm{DTT}$, and $20 \mu \mathrm{g} / \mathrm{ml}$ poly $\mathrm{d}(\mathrm{I}-\mathrm{C})]$ and subsequently incubated with $0.25 \mathrm{ng}(30,000-40,000$ Cerenkov's cpm) of end-labeled probe for $20 \mathrm{~min}$ at room temperature. Commercially available double-stranded oligonucleotides (Stratagene, La Jolla, CA; Santa Cruz Biotechnology, Santa Cruz, CA) containing binding motifs for the transcription factors AP-1, ZIF 268, and CREB were selected. AP-1:

5'-CTA GTG ATG AGT CAG CCG GATC-3'

3'-GAT CAC TAC TCA GTC GGC CTAG-5'

$\angle I F{ }^{268:}$

5'-GGA TCC AGC GGG GGC GAG CGG GGG CGA-3'

$3^{\prime}$-CCT AGG TCG CCC CCG CTC GCC CCC GCT-5'

CRE:

5'-GAT TGG CTG ACG TCA GAG AGCT-3'

$3^{\prime}$-CTA ACC GAC TGC AGT CTC TCGA-5'

SP-1:

5'-ATT CGA TCG GGG CGG GGC GAG-3'

$3^{\prime}$ TA CGT AGC CCC GCC CCG CTC-5' mt AP-1:

ATG ACT TGG

TAC TGA ACC

mt ZIF 268:

AGC TAG GGC GAG CTA GGG CGA

ICG A'IC CCG C"IC GA'I CCC GCl'

Binding motifs are underlined, and substitutions in binding motifs are in bold italic. The mutant sequences were used as controls (mutant binding motifs are shown on the right). All probes were end-labeled with $\left[{ }^{32} \mathrm{P}\right] \mathrm{dATP}$ (DuPont NEN, Boston, MA) using polynucleotide kinase
(Boehringer Mannheim, Indianapolis, IN) and purified on Nuctrap push columns (Stratagene, La Jolla, CA). A series of control experiments was performed to assess the specificity of binding. These involved competition with an excess of unlabeled probe, mutant sequences, or unrelated SP1 oligonucleotides.

After incubation, $2 \mu \mathrm{l}$ of loading buffer containing $0.3 \%$ bromophenol blue $/ 3 \%$ glycerol was added to the samples and electrophoresed at $130 \mathrm{~V}$ for $2 \mathrm{hr}$ in a nondenaturing $4 \%$ polyacrylamide gel. Electrophoresis was performed in a low ionic strength buffer $(6.7 \mathrm{~mm}$ Tris- $\mathrm{HCl}, \mathrm{pH} 7.5,1 \mathrm{~mm}$ EDTA, and $3.3 \mathrm{~mm}$ sodium acetate). Gels were dried and exposed to autoradiographic film (Amersham, Arlington Heights, IL) with intensifying screens at $-70^{\circ} \mathrm{C}$ overnight. To facilitate comparison among the different conditions, the autoradiograms were scanned densitometrically and average gray/pixel level was measured in the area of the band.

Supershift analysis. EMSA-supershift analysis was performed to identify the components of the AP-1 complex using procedures that we have used previously (Kaminska et al., 1994, 1995; Lukasiuk and Kaczmarek, 1994). Commercially available (Santa Cruz) polyclonal antibodies against the following members of the AP-1 family were used: c-Fos (sc-52X), FosB (sc-48X), Fra-2 (sc-171X), c-Jun (sc-822X), JunB (sc-46X), and JunD (sc-74X). All antibodies $(1 \mathrm{mg} / \mathrm{ml})$ were affinity-purified by the manufacturer and had no detectable cross-reactivity with other members of the Fos and Jun families. This was confirmed by our Western blot analysis and preincubation of protein extracts with blocking peptides (Santa Cruz) corresponding to each antibody (data not shown). A polyclonal antibody was used in the binding experiment for Zif 268 (gift from R. Bravo, Bristol-Myers Squibb, Princeton, NJ).

One microliter of each antibody was added to $10 \mu \mathrm{l}$ of reaction volume containing the nuclear protein extract $(10 \mu \mathrm{g})$ and incubated for $1 \mathrm{hr}$ at $4^{\circ} \mathrm{C}$. Afterward, the labeled oligonucleotide was added to the reaction mixture and the EMSA protocol was followed as described above. The samples were then electrophoresed at $110 \mathrm{~V}$ for $5 \mathrm{hr}$ with recirculation of the electrophoresis buffer. Gels were dried and exposed to autoradiographic film (Amersham) with intensifying screens at $-70^{\circ} \mathrm{C}$ overnight.

Immunocytochemistry. For immunocytochemistry, the brains were cxtracted after decapitation and blocked at the midpoint along the anterior-posterior axis. The occipital block was then immediately frozen in an isopentane/dry ice bath. The tissue was sectioned at $20 \mu \mathrm{m}$ on a cryostat, dried overnight, and fixed in $4 \%$ paraformaldehyde for 5 min before immunostaining. The sections were treated to a primary antibody solution containing either the c-Fos (Santa Cruz, sc-52X) or Zif 268 antibody at dilutions of $1: 2000$ and $1: 10,000$, respectively, in $0.01 \mathrm{MPBS} / 3 \%$ normal goat serum. After incubation for $48 \mathrm{hr}$ at $4^{\circ} \mathrm{C}$, the sections were washed in PBS containing $0.3 \%$ Triton X-100 and incubated in $0.1 \%$ goat antirabbit antibody in Triton-PBS for $2 \mathrm{hr}$ at room temperature. After another wash in PBS, the sections were then incubated in a solution of avidin-biotin-conjugated horseradish peroxidase complex (Vector Laboratories, Burlingame, CA) for $1 \mathrm{hr}$ at room temperature. Sections were then subjectcd to a nickel-enhanced diaminobenzidine (DAB) reaction that resulted in a dark blue stain within c-Fos- and Zif 268immunoreactive neurons. The primary antibody was absent in control sections, which were otherwise processed identically.

\section{RESULTS}

The results of this study will be considered in three areas that reflect methodological differences-EMSA, EMSA-supershift, and immunocytochemistry. We were primarily interested in examining the details of AP-1 induction and how light stimulation may have differential effects on its various members. We also sought to obtain the temporal profiles of two other transcription factors, ZIF 268 and CREB. Both of these products have been implicated in a number physiological mechanisms through transcriptional regulation.

\section{Effects of visual stimulation on ZIF 268 induction}

Selective light stimulation produced significant effects on ZIF 268 induction in rat visual cortex, as can be seen from the banding patterns in level I of Figure 1 $\mathrm{A}$. The basal level of ZIF 268 DNAbinding activity was relatively high in the visual cortex of naive rats. Dark rearing for $7 \mathrm{~d}$ produced a decrease in the band intensity in one animal and a negligible difference in the other when compared with the naive animals. Visual exposure after dark rearing resulted in 
A

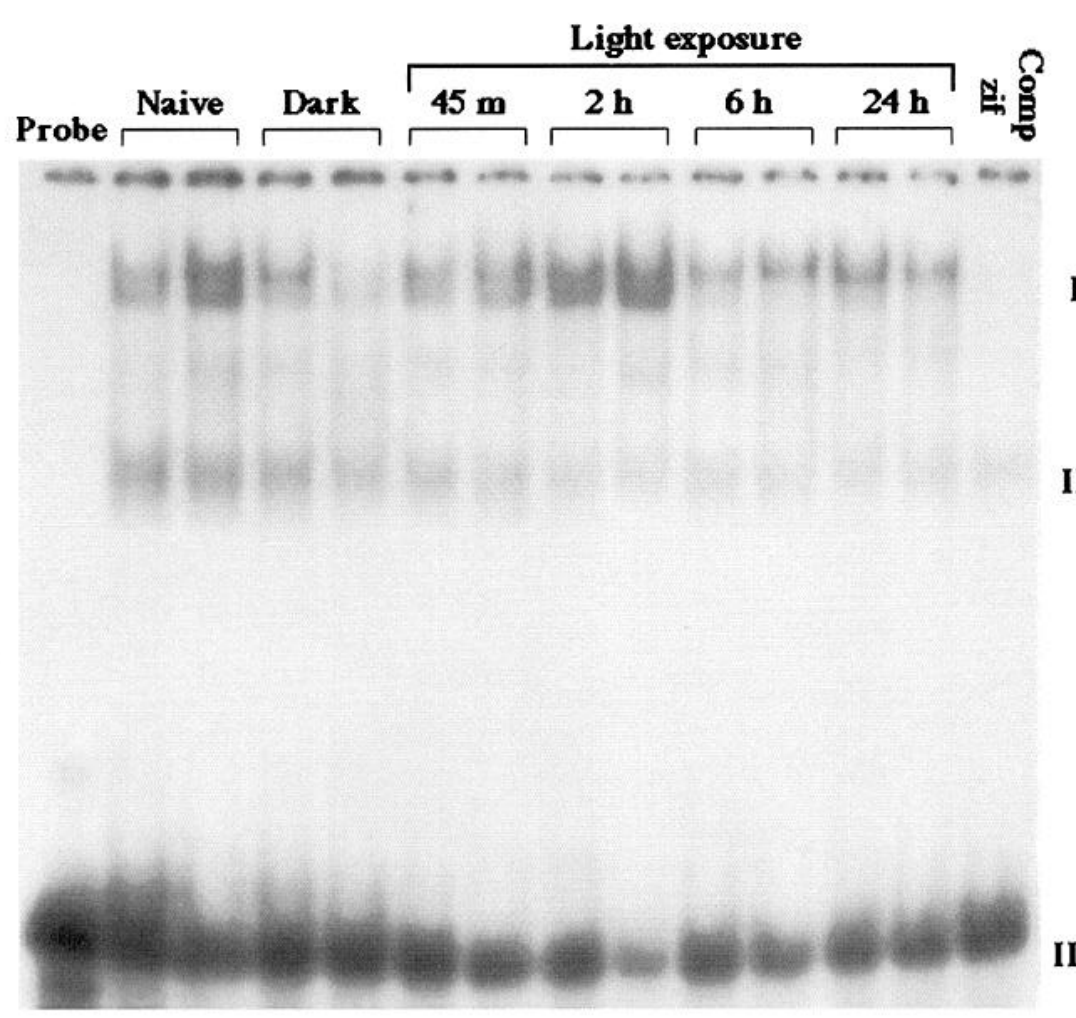

B

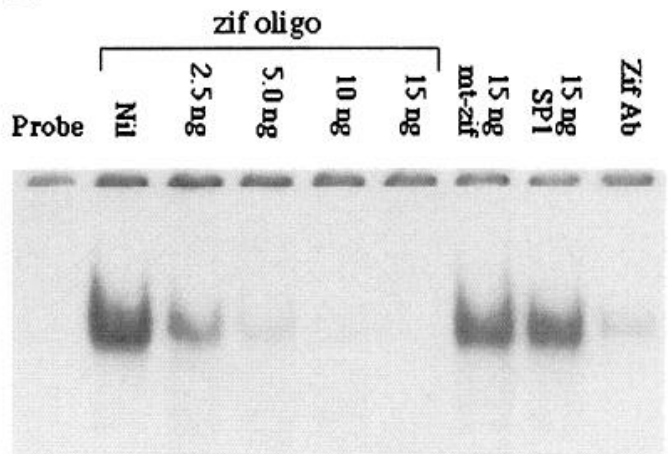

II

III

Figure 1. The levels of ZIF 268 DNA-binding activity in nuclear extracts from visual cortex of rats exposed to different light conditions. $A$, EMSA reactions were made using $20 \mu \mathrm{g}$ of nuclear extracts from two different animals for each condition. The retarded bands in the level marked $I$ represent the specific ZIF 268 DNA-binding activity. B. Competition studies showing the specificity of binding to ZIF 268 consensus sequence. The first lane (Probe) shows $0.25 \mathrm{ng}$ of end-labeled probe without extract; the second ( Nil) shows the retardation of the ZIF 268 probe caused by nuclear proteins from visual cortex of rats exposed to light for $2 \mathrm{hr}$ in the absence of unlabeled probe. In the following lanes, this retarded band is specifically inhibited by progressively increasing amounts of unlabeled ZIF 268 oligonucleotide. The inclusion of 15 ng of mutant ZIF 268 and SP-1 oligonucleotides, representing a 60 -fold excess, failed to inhibit binding. The inclusion of antibody against ZIF 268 protein diminished binding.

increased short-term ZIF 268 DNA-binding activity. Light stimulation for as little as 45 min elevated the ZIF 268 DNA-binding activity to the level seen in naive rats. After $2 \mathrm{hr}$, this level was found to be even greater. This induction effect, however, appears to be transient because the band intensities became significantly reduced and returned to basal levels in animals that received 6 and $24 \mathrm{hr}$ of light stimulation. We confirmed that the changes in the levels of the ZIF 268 DNA-binding activities reflected alterations in the levels of functionally active form of the transcription factor by way of Coomassie staining of PAGE gels run in parallel. This was used to verify that each lane was loaded with the same amount of total protein (data not shown).

The evidence for the specificity of the binding was obtained from various sets of controls that were applied during these experiments. First, addition of excess unlabeled probe to the reaction mixture before gel shift assay reduced band I due to competition with the available protein. Addition of progressively greater amounts of unlabeled probe showed a corresponding decrease in the intensity of level I banding (Fig. 1B). Second, although a 60 -fold excess of unlabeled probe significantly reduced band intensity, similar amounts of mutant zif 268 oligonucleotide (mt-zif) and SP-1 oligonucleotide (arbitrary probe) had negligible effects. Third, the addition of $0.5 \mu \mathrm{g}$ of anti-Zif 268 polyclonal antibody to the reaction mixture reduced probe-protein binding because of a possible hindrance at the DNA-binding site (last lane in Fig. 1B). Tissue was obtained from rats exposed to light for $2 \mathrm{hr}$ after dark rearing for all of the conditions shown in Figure $1 B$. We have conducted the same set of controls on tissue from animals that were dark-reared only and have obtained identical results. Taken together, these findings attest to the specificity of the EMSA results and allow confident evaluation of the banding patterns obtained under various conditions of stimulation.

We were interested in confirming the results of the dark rearing and $2 \mathrm{hr}$ light exposure conditions in additional animals, because these represented the extreme boundaries of ZIF 268 expression. As Figure 2 shows, 4 out of 5 animals in the dark rearing condition showed significantly reduced band intensities. The aberrant case was the same animal that was represented in Figure $1 A$. It is likely that this reflects individual variation among animals because both the quality and the content of protein extract were equal in each lane. All 5 animals receiving $2 \mathrm{hr}$ of light exposure, however, showed elevated levels of ZIF 268 DNA-binding activity. The specificity of the banding patterns was again assessed by competition conditions. A 60 -fold excess of unlabeled probed reduced band intensity, whereas similar amounts of mutant zif 268 oligonucleotide had negligible effects.

\section{Effects of visual stimulation on AP-1 and CRE DNA-binding activity}

The EMSA profiles of AP-1 consensus binding are shown in Figure 3. Animals that were dark-reared for $7 \mathrm{~d}$ did not show significant differences in AP-1 DNA-binding activity compared 


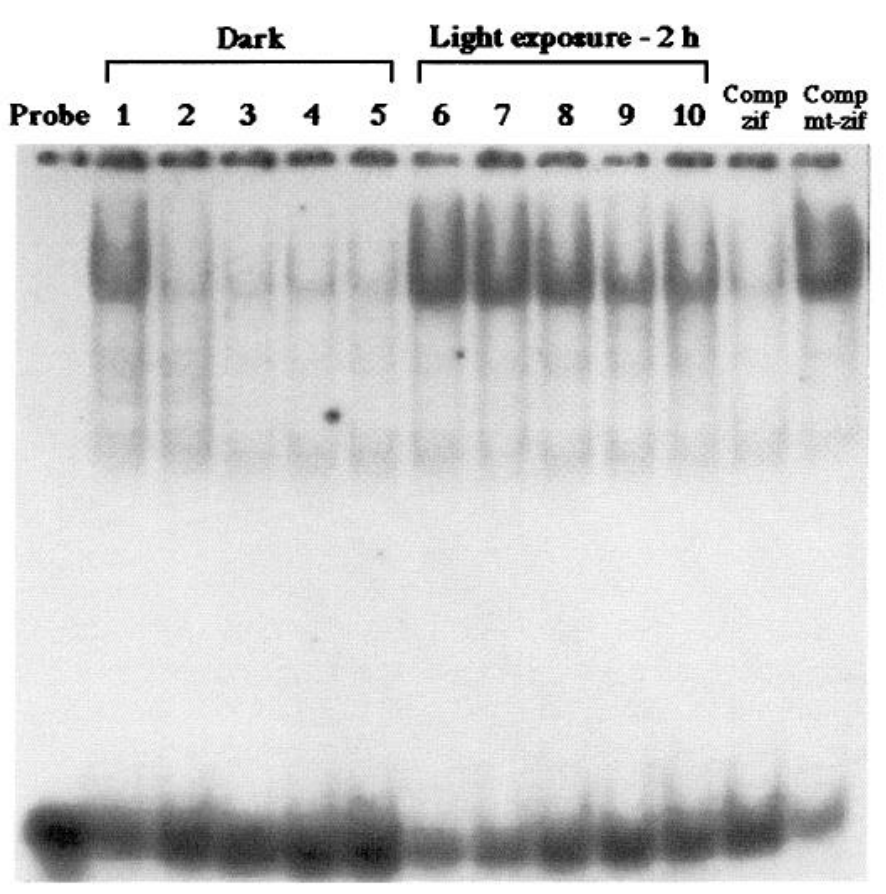

Figure 2. The reproducibility of increased ZIF 268 DNA-binding activity in visual cortex by light stimulation. Representative autoradiogram showing the level of ZIF 268 DNA-binding activity in visual cortices of five rats kept 1 week in darkness and another five that were dark-reared and then exposed to light for $2 \mathrm{hr}$. The specificity of the binding was shown by a competition experiment with a 60-fold excess of unlabeled ZIF 268 consensus sequence. Excess mutant ZIF 268 oligonucleotide had no effect on binding protein extract (rat 6 ).

with naive animals (Fig. $3 A$ ). In both cases, there was a discernible band in the two animals that were tested for each condition, indicating low basal DNA-binding activity. Light stimulation produced a significant increase in AP-1 DNA-binding activity within $2 \mathrm{hr}$ of exposure. The band intensities remained high for both the 6 and $24 \mathrm{hr}$ light exposure conditions. As with ZIF 268, we confirmed specificity by way of competition experiments. A 10 fold excess of unlabeled oligonucleotide (Comp AP-1) abolished the appearance of the retarded band, whereas mutant AP-1 and SP-1 probes had negligible effects (Fig. $3 B$ ).

To investigate whether stimulus-induced increase in AP-1 DNA-binding activity was restricted to visual cortex, we quantified the band intensities from the profiles obtained in both visual and frontal cortex by densitometric scanning of the gel shift autoradiograms. Figure $3 C$ shows the averaged AP- 1 levels that were present under the different light conditions in both brain areas. The AP-1 levels in this figure have been normalized to the densitometric values for CRE-binding activity for the same exposure condition and are expressed in arbitrary units. AP-1 DNAbinding activity after $45 \mathrm{~min}$ of light stimulation was similar to the naive and dark conditions. However, AP-1 levels peaked after $2 \mathrm{hr}$ of light exposure and remained elevated after 6 and $24 \mathrm{hr}$. This was not the case, however, in frontal cortex where, although there was an elevated presence of AP-1, this level was not affected by the different conditions of light exposure.

The light-dependent changes in DNA-binding activities of AP-1 and ZIF 268 transcription factors in visual cortex were not accompanied by a similar increase in DNA-binding activities of CREB-related proteins. As Figure 4 shows, DNA-binding activity to the CRE consensus remained unchanged in naive, dark-reared, and light-exposed animals. Competition with unlabeled CRE sequence (Comp CRE) again abolished this band. CRE binding, therefore, may serve as an internal control of the quality and quantity of nuclear proteins because an accurate depiction of stimulation effects requires that all samples contain equal amounts of nuclear extracts. The CRE-binding results were used, therefore, to verify this requirement and confirm the colorimetrybased procedure of Coomassie blue staining of protein gels that were run in parallel with the EMSA experiments.

\section{Protein composition of AP-1 assessed by EMSA-supershift}

EMSA-supershift experiments were initiated to determine the composition of the induced AP-1 complex. Affinity-purified polyclonal antibodies that are specific for the various members of the Fos and Jun families were added to the reaction mixture before gel shift assay. Because all antibodies were made against a portion of the protein that is not important for DNA binding, the presence of a more slowly migrating "supershifted" band reflects the presence of a particular member of the AP-1 complex within the nuclear extract. We performed this procedure on 5 rats for each exposure condition ( 2 animals at $6 \mathrm{hr}$ ) and obtained similar results.

Figure 5 shows the AP-1 EMSA-supershift results in two representative animals for each of five treatment conditions: naive, dark, and 2, 6, and $24 \mathrm{hr}$ light exposure. The most striking result from this experiment was the differential induction of the various AP-1 components produced by light stimulation. The composition of the AP-1 complex in visual cortex of both naive and darkreared animals was similar in that only the FosB and JunD antibodies produced a visible supershifted band (arrows in Fig. 5). This suggests that, under these conditions, nearly all of the AP-1 DNA-binding activity may be accounted for by a combination of the FosB and JunD proteins. Furthermore, we have consistently found that dark rearing produces increased levels of JunD, as can be seen by the intense supershifted band in this condition in Figure 5 .

Light exposure for $2 \mathrm{hr}$ produced a transient induction of c-Fos and JunB, although FosB and JunD were still present at substantial levels (Fig. 5). After $6 \mathrm{hr}$ of light exposure, c-Fos content was found to be significantly reduced, although FosB, JunB, and JunD remained elevated and became the major components of the AP-1 complex. After $24 \mathrm{hr}$, c-Fos levels became negligible, whereas the elevated levels of FosB and JunD remained unchanged. There was little evidence for Fra-2 induction under any of these conditions. The c-Fos antibody did not produce a supershifted band with a CRE consensus, and removal of the antibodies in all conditions eliminated the supershifted bands. These served as additional controls to verify the specificity of the observed effects.

EMSA-supershift analysis for c-Jun has been difficult in the past because of the lack of an antibody with the appropriate binding characteristics. With the availability of such an antibody, it is now possible to examine the contribution of c-Jun to the AP-1 complex under different conditions of visual stimulation. We have examined this issue with respect to light-induced expression in the rat visual system and have found that, as with c-Fos, c-Jun was transiently expressed (Fig. 6). Indeed, c-Jun is induced to its highest levels after $2 \mathrm{hr}$ of light stimulation after dark rearing, as indicated by the supershifted bands in Figure 6 , and became negligible after 6 and $24 \mathrm{hr}$ (see Fig. 5 for the latter condition). This figure shows 2 representative animals out of a total of 4 that were treated to each of the stimulation conditions. The naive 
A

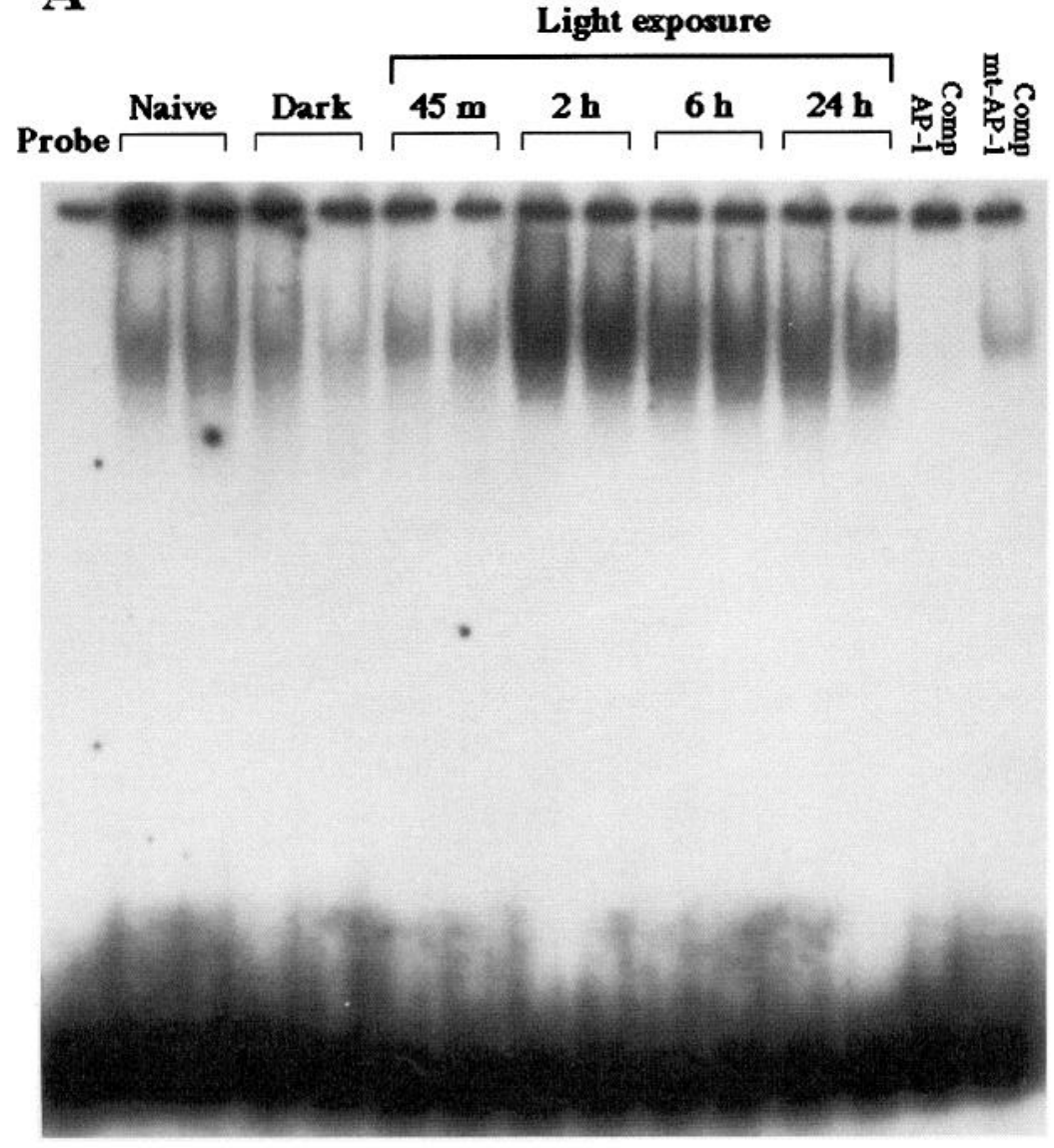

B

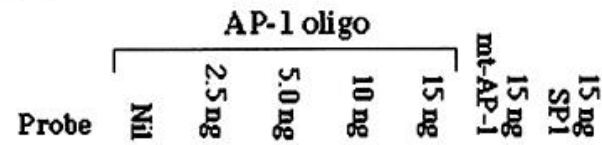

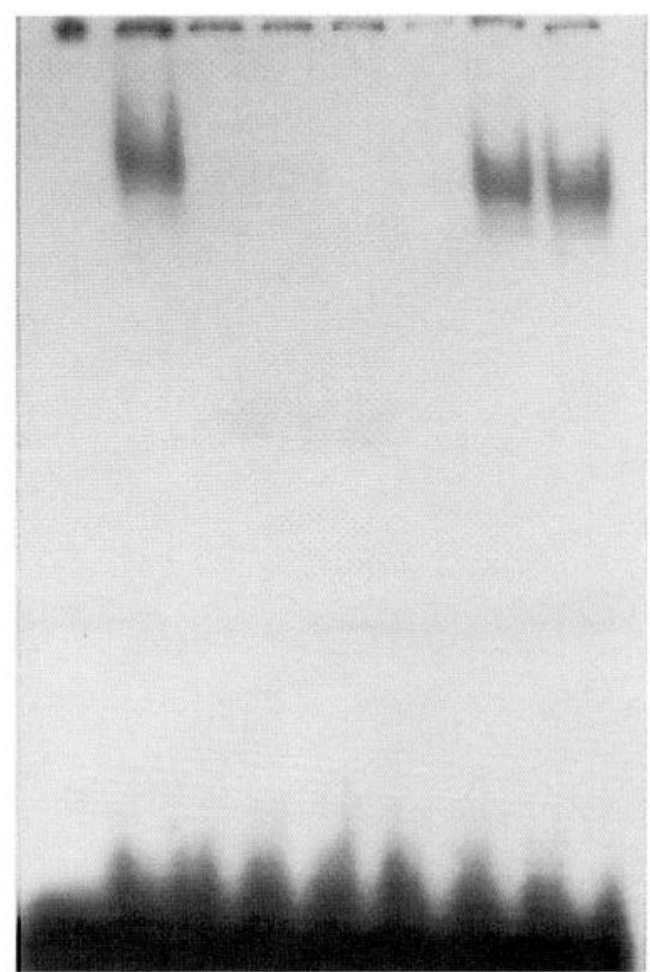
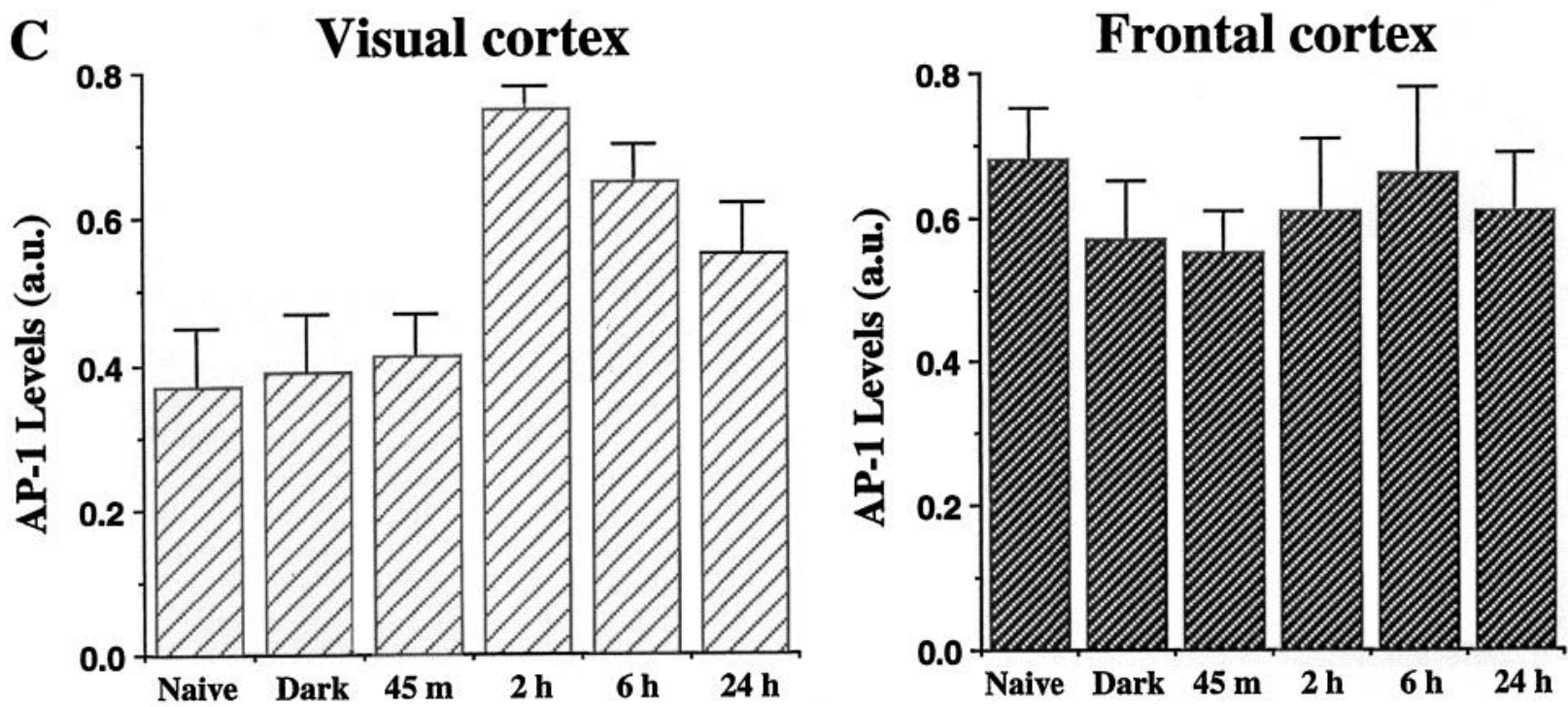

Figure 3. The levels of AP-1 DNA-binding activity in nuclear extracts from visual cortex of rats exposed to different light conditions. $A$, EMSA reactions using $20 \mu \mathrm{g}$ of nuclear extracts from two different rats. $B$, Competition studies showing the specificity of binding to AP-1 consensus sequence. The first lane (Probe) shows $0.25 \mathrm{ng}$ of end-labeled probe without extract; the second (Nil) shows the retardation of the AP-1 probe caused by nuclear proteins from visual cortex of rats exposed to light for $2 \mathrm{hr}$ in the absence of unlabeled probe. In the following lanes, this retarded band is specifically inhibited by progressively increasing amounts of unlabeled AP-1 oligonucleotide. The inclusion of $15 \mathrm{ng}$ of mutant AP-1 and SP-1 oligonucleotides, representing a 60 -fold excess, failed to inhibit binding. $C$, Densitometry-based analysis of AP-1 DNA-binding activity levels in visual and frontal cortices of rats exposed to various light conditions. EMSA reactions with AP- 1 consensus sequence were carried out in parallel with nuclear extracts from visual $(n=5$ for all groups) and frontal cortex ( $n=5$ for Naive, $n=3$ for both Dark and Light groups of various durations). Naive, Animals kept under normal dark/light cycle and killed during the light phase; Dark, animals kept for $7 \mathrm{~d}$ in complete darkness and killed in the darkness; Light, animals kept for $7 \mathrm{~d}$ in complete darkness and killed after $45 \mathrm{~min}$ and 2, 6, and $24 \mathrm{hr}$ exposure to light. The results shown are means expressed in arbitrary units (a.u.) of AP-1 densitometry values that were normalized to those obtained for CRE-binding activity under similar exposure conditions. Error bars represent SD. 


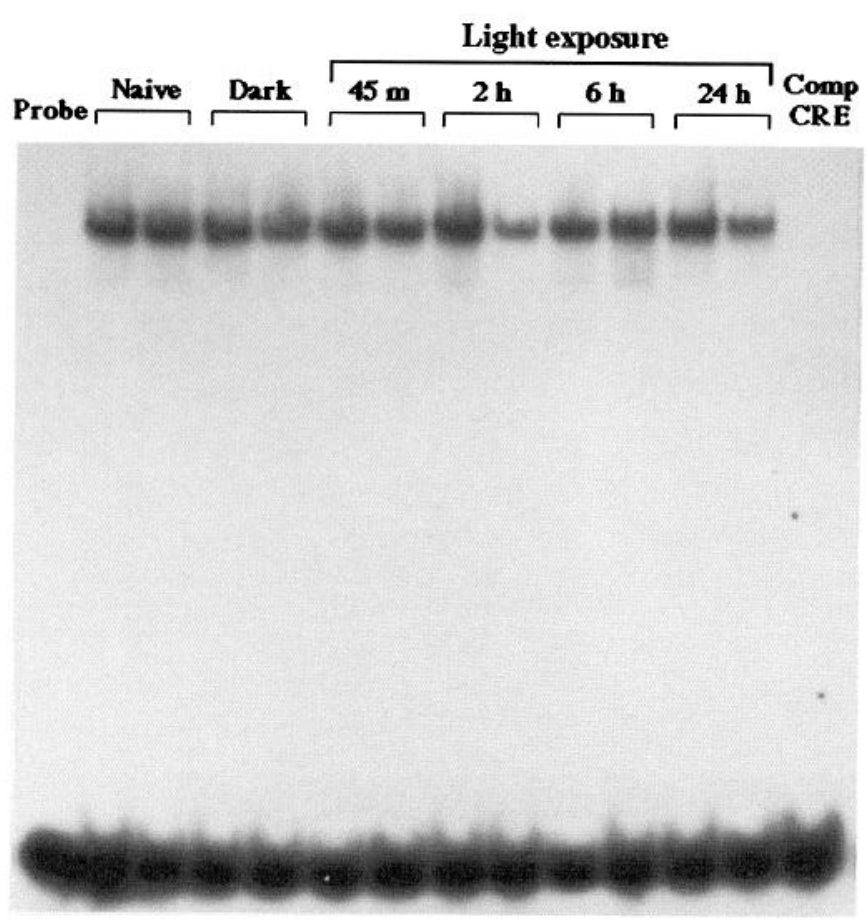

Figure 4. The levels of CRE DNA-binding activity in visual cortex of rats exposed to different light conditions. EMSA reactions with CRE consensus sequence were carried out in parallel with the same amount of protein extracts as for ZIF 268 and AP-1. The figure illustrates that CRE DNAbinding activity remained unaffected under the different light conditions. The lane marked as Comp CRE shows that a 20 -fold excess of unlabeled $\mathrm{CRE}$ consensus sequence abolished the retarded band.

animals showed low basal expression that seemed to disappear after prolonged dark rearing $(7 \mathrm{~d})$. These results suggest that the temporal dynamics of c-Jun contribution to the AP-1 complex are similar to that of c-Fos and that both play a major role in visual cortical neurons that are activated after a period of quiescence.

\section{Immunocytochemical localization of Zif $\mathbf{2 6 8}$ and c-Fos}

We wished to observe the spatial distribution of Zif 268 and c-Fos induction across the visual cortex after light exposure. We used monocularly enucleated rats so that one hemisphere served as a within-animal control. As with the EMSA experiments, animals were initially dark-reared and then exposed to light, although for only $2 \mathrm{hr}$. As a control, additional monocularly deprived animals were either left under normal light/dark cycle or killed after dark rearing only. Figure 7 presents the results of c-Fos immunostaining on the light-exposed animals. The contralateral hemisphere clearly showed elevated c-Fos expression throughout the visual cortex, as expected because the neurons here were receiving afferent stimulation. In the ipsilateral hemisphere, however, immunostaining was confined to a narrow zone in the binocular representation of Oc1 (Zilles et al., 1984). There was little c-Fos immunoreactivity elsewhere in the ipsilateral visual cortex. A band of immunostained cells is also visible within the superior colliculus contralateral to the intact eye. The dark- and lightcontrol animals showed no c-Fos immunoreactivity in either the visual cortex or the superior colliculus. These results show that visual input evokes c-Fos expression but only under the condition of light stimulation after dark rearing and confirms the EMSAsupershift results above. We did not detect such dramatic changes in any of the other AP-1 components with immunocytochemistry.
The Zif 268 immunostaining profile was somewhat different, as expected (Fig. 8). Light exposure produced intense staining within the binocular representation of Oc1 on the ipsilateral side. This was flanked by the poorly stained monocular representation. However, the remaining regions on the ipsilateral side showed significant Zif 268 immunostaining, revealing a high level of constitutive expression that has been noted previously (Worley et al., 1990, 1991). Staining in the contralateral hemisphere was more intense than with c-Fos and was not restricted to the primary and secondary visual areas only. The results in the superior colliculus, however, are similar to those with c-Fos. There is little constitutive expression in this structure as revealed by the poor staining in the ipsilateral colliculus. However, on the contralateral side, there was again a band of immunostained cells along the dorsal margin. The light-control animals showed high levels of Zif 268 immunoreactivity throughout the visual cortex, whereas the dark-control animals showed reduced immunostaining.

\section{DISCUSSION}

The major finding of this study was that alterations of visual input result in specific changes to the DNA-binding activities of AP-1 and ZIF 268 in the visual cortex. We have found that visual input not only regulates the level of transcription factors but also modulates the composition of the AP-1 complex by selective induction of particular Fos and Jun family members. This may be a consequence of differences in the molecular mechanisms that guide stimulus-transcription coupling of the candidate genes, as discussed below. The quality of extracted nuclear protein in all cases was ensured by comparison with CRE DNA binding activity, and gel-loading consistency was verified through Coomassie blue staining of protein gels run in parallel.

\section{Comparison with previous studies}

Our results are in general agreement with previous demonstrations of changes in transcription factor mRNA and proteins that are driven by visual input in rat, cat, and monkey visual cortex (Worley et al., 1990, 1991; Beaver et al., 1992; Rosen et al., 1992; Chaudhuri and Cynader, 1993; Mower, 1994; Chaudhuri et al., 1995a). It is known that blockade of afferent activity by intraocular injection of-TTX results in pronounced reductions of zif 268 mRNA and immunoreactivity in visual cortex of adult rats and monkeys (Worley et al., 1990, 1991; Chaudhuri et al., 1995a). Furthermore, Worley et al. $(1990,1991)$ have shown that reducing visual activity by placing animals in the dark decreases levels of zif 268 mRNA and that immunoreactivity and reexposure to light returned them to the basal levels.

In contrast to the rapid suppression of zif 268 mRNA in the brain by NMDA antagonists or blockade of retinal activity, several other transcription factors, including AP-1, are relatively unaffected by these treatments (Worley et al., 1990, 1991). With respect to upregulation of AP-1 components, Rosen et al. (1992) have shown that c-fos and junB mRNA levels are transiently elevated with light stimulation in kitten visual cortex. However, they noted that c-jun mRNA levels were not affected by this treatment. Contrary to this finding, we have found that c-Jun, along with c-Fos and Jun B, were responsible for the elevated AP-1 DNA-binding activity in rat visual cortex after light stimulation. Our finding of c-Jun induction corroborates recent findings that c-Jun phosphorylation regulates its presence within the AP-1 complex (for review, see Hunter and Karin, 1992; Davis, 1993).

Our results on c-Fos expression, based on both immunocytochemistry and EMSA-supershift, confirm and extend to the adult 

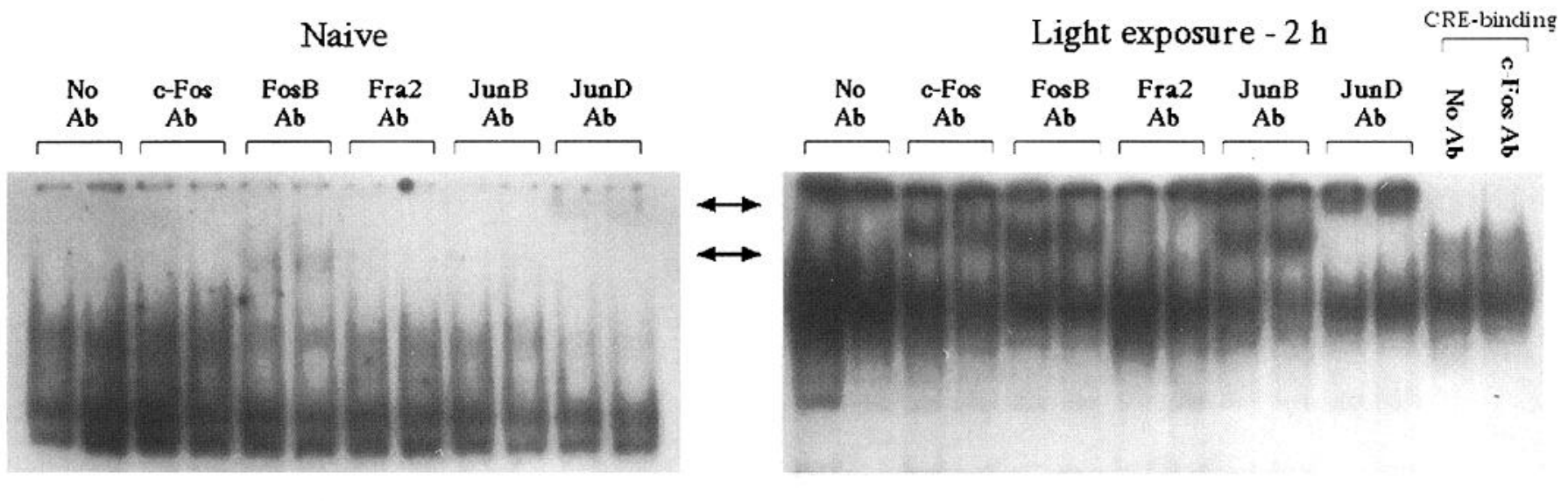

Dark
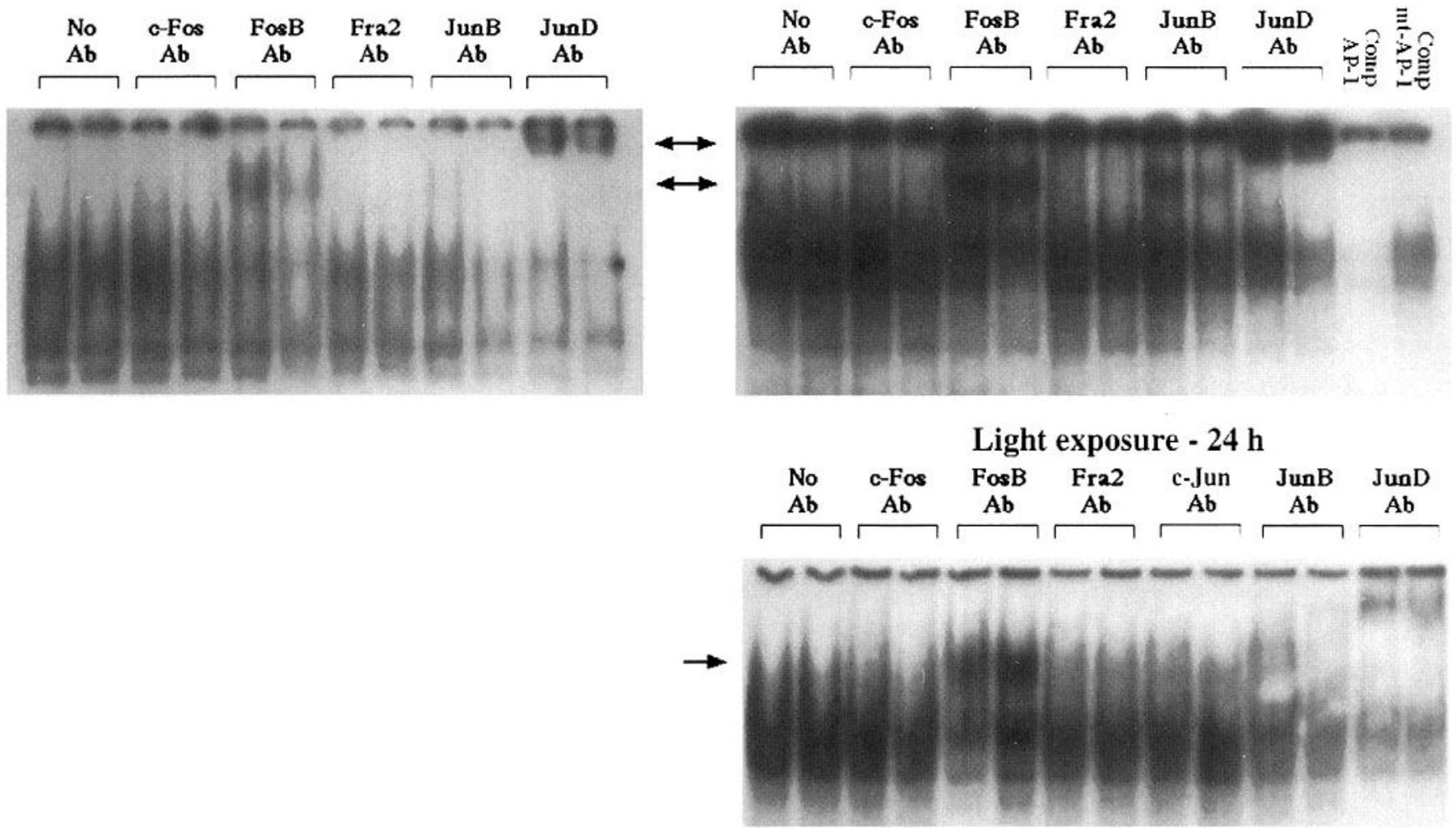

Figure 5. The protein composition of the AP-1 transcription factor in visual cortex of rats. Ten micrograms of protein extract from naive, dark-reared, and light-reared rats exposed to light for 2,6, or $24 \mathrm{hr}$ were subjected to EMSA-supershift analysis. The results are shown for two animals for each condition. The designations at the top indicate which antibody was added to each sample. The supershifted bands, the positions of which are indicated with arrows, show the participation of specific proteins in the AP-1 complex. As a negative control, the inclusion of antibody against c-Fos had no effect on binding to the CRE consensus sequence in animals that were light-exposed for $2 \mathrm{hr}$. The specificity of the AP-1 binding was confirmed by competition assay with 20-fold excess of unlabeled AP-1 or mutant AP-1 oligonucleotides and performed on nuclear extracts from animals with 6 hr of light exposure.

rat those findings that were reported by Beaver et al. (1993) and Mower (1994) in the cat. These observations strengthen the evidence for a link between the expression of selected transcription factors and neuronal activity.

\section{Regulation of transcription factors by synaptic stimulation: comparison of AP-1 and ZIF 268}

The analysis of DNA-binding activities of different transcription factors has revealed clear differences in the expression profiles of ZIF 268 and AP-1 transcription factors under different light conditions. In contrast to AP-1, the basal level of ZIF 268 was high in visual cortex of rats kept under standard light/dark conditions. Rearing rats for $7 \mathrm{~d}$ without visual input significantly reduced the level of ZIF 268 DNA-binding activity in visual cortex. The same condition had little effect on the AP-1 DNAbinding activity. Light exposure caused an increase in DNAbinding activities of both transcription factors, but with different temporal profiles. ZIF 268 levels increased to a maximum after 2 hr of visual exposure. Continued stimulation for $24 \mathrm{hr}$, however, returned this to basal levels similar to that in the naive animals. AP-1 DNA-binding activity remained elevated even after $24 \mathrm{hr}$ of exposure.

Immunocytochemical studies further confirmed the visual input specificity of the increases of c-Fos and Zif 268 proteins. We have found that only the brain areas receiving a light-driven afferent 

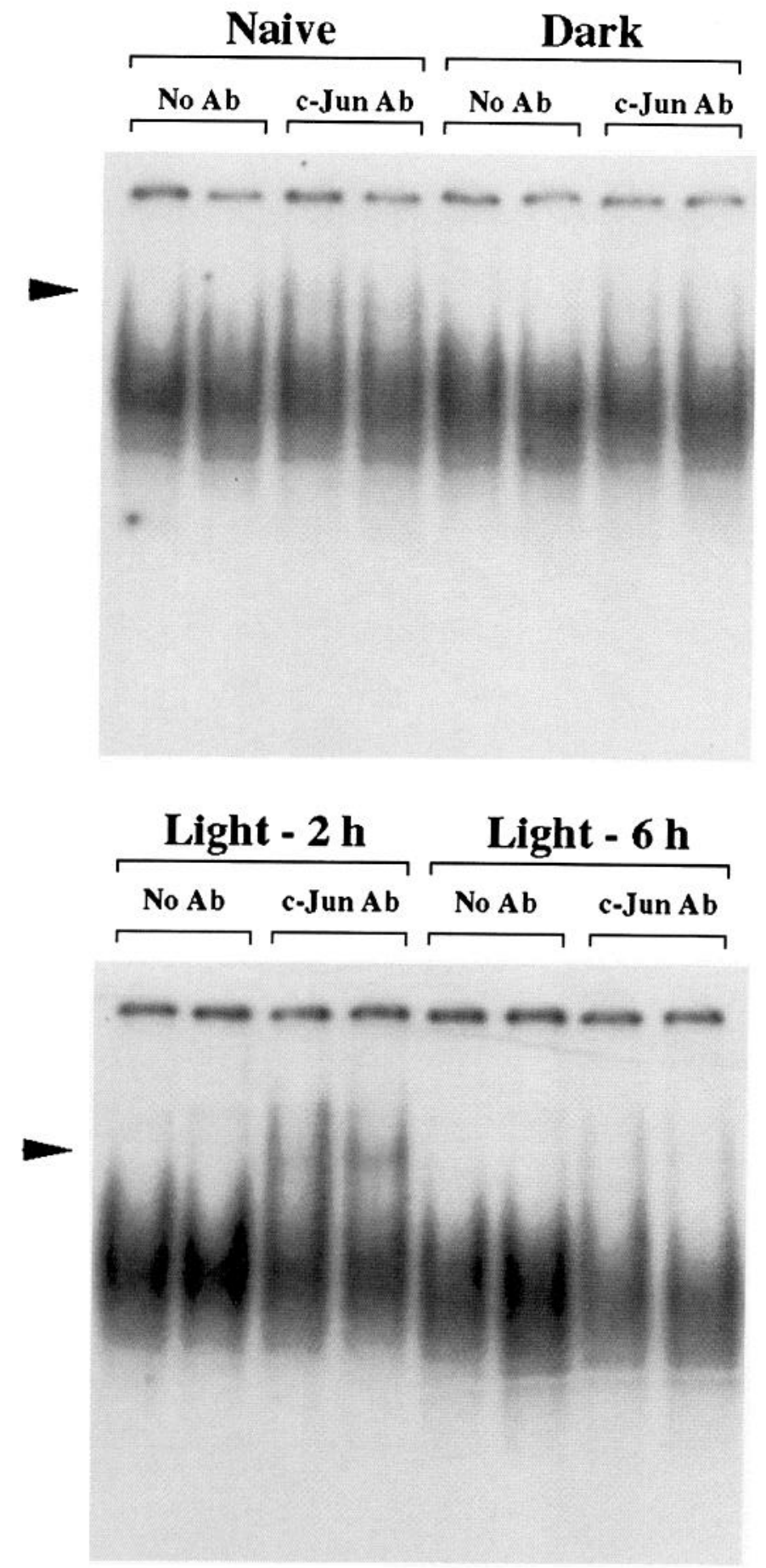

Figure 6. EMSA-supershift analysis of c-Jun. Ten micrograms of protein extract from naive, dark-reared, and light-reared rats exposed to light for 2 or $6 \mathrm{hr}$ were subjected to EMSA-supershift analysis. The results are shown for two representative animals out of a total of four that were tested for each light exposure condition. A discernible supershifted band at the level of the arrowhead is evident $2 \mathrm{hr}$ after light exposure, whereas bands of reduced intensity are present in naive animals and those exposed to light for $6 \mathrm{hr}$. The dark-reared animal failed to show a c-Jun-supershifted band. The control conditions (no antibody to reaction mixture) also did not yield a supershifted band.

signal showed increased immunostaining for both products. This was particularly dramatic in the case of c-Fos, in which no constitutive expression was discernible in visual cortex and yet stimulus-driven expression was clearly evident only in animals that had been dark-reared before visual stimulation. This feature of c-Fos expression is different from that of Zif 268, in which there is a high degree of constitutive expression and the levels of which are adjusted by the magnitude of ongoing neural activity. Our finding of activity-driven expression of both c-Fos and Zif 268 in the superior colliculus, with little constitutive expression for either, suggests that a common mechanism may exist for their transcriptional regulation in this visual structure. This finding also provides further evidence for adding superior colliculus to the list of the visual structures (retina, suprachiasmatic nucleus, and lateral geniculate nucleus) where light input upregulates c-Fos and/or Zif 268 expression (Aronin et al., 1990; Rusak et al., 1990; Sagar and Sharp, 1990; Beaver et al., 1993).

\section{AP-1 and ZIF 268 as regulators of long-term change}

The different temporal and stimulus-dependent expression profiles of AP-1 and ZIF 268 are suggestive of the different roles of these transcription factors in regulating neuronal function. It has been proposed that activation of c-Fos simply reflects neuronal activity and that its spatial expression may be used, therefore, as an imaging tool to map activated neurons (Sagar et al., 1988; Dragunow and Faull, 1989). A similar function has been proposed for Zif 268 (Worley et al., 1991; Chaudhuri et al., 1995a). Our results support the notion that the expression of ZIF 268 is modulated by neural activity triggered by visual input, whereas AP-1 induction requires neural activity to be initiated only after a period of quiescence. Although we have used a $7 \mathrm{~d}$ period of dark rearing to achieve this, recent evidence in monkey visual cortex suggests that $4 \mathrm{hr}$ is sufficient to trigger $c$-fos mRNA expression (Chaudhuri et al., 1995b).

A growing body of evidence suggests that patterned activation of specific components of the AP-1 transcription factor may provide the means by which specific changes in neuronal responses may be generated (Sheng and Greenberg, 1990; Morgan and Curran, 1991, 1995; Kaczmarek, 1993). The specificity of transcription may be generated by selective combinatorial interactions of different members of the Fos and Jun families. In vitro studies have shown that there are a large number of Fos related proteins capable of dimerizing with Jun proteins to form AP-1 complexes in addition to the Jun-Jun homodimeric combinations (Ryseck and Bravo, 1990). This large number of potential dimer combinations, therefore, would allow for a variety of AP-1 complexes, each with perhaps a different DNA-binding characteristic, half-life, and transcriptional control (Angel and Karin, 1991). Consistent with this hypothesis, it has been shown that dynamic alterations in the levels of different AP-1 components occur after seizure (Sonnenberg et al., 1989; Gass et al., 1993; Hope et al., 1994; Kasof et al., 1995). Furthermore, the composition of the induced AP-1 complex is different with neuronal activation after kainate-evoked seizures than with kainate-induced neurodegeneration (Kaminska et al., 1994).

In this study, we have found evidence for a constitutive presence of AP-1 hetero- and/or homodimers containing FosB and JunD proteins in the visual cortex of dark-reared rats. The induction of c-Fos-, c-Jun-, and JunB-containing complexes correlated with early events after visual stimulation of dark-reared rats and resembled the composition of the AP-1 complex observed in early neuronal activation after seizures (Kaminska et al., 1994; Kasof et al., 1995). The combinations of FosB, JunB, and JunD proteins constitute the AP-1 DNA-binding activity in the late phase after light exposure. Given that different AP-1 complexes may have 


\section{c-Fos}

\section{Contralateral}

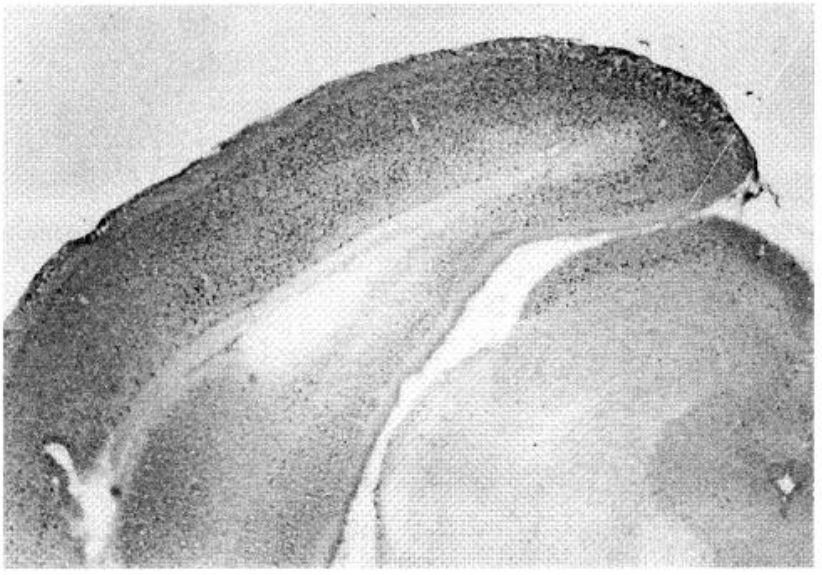

Ipsilateral

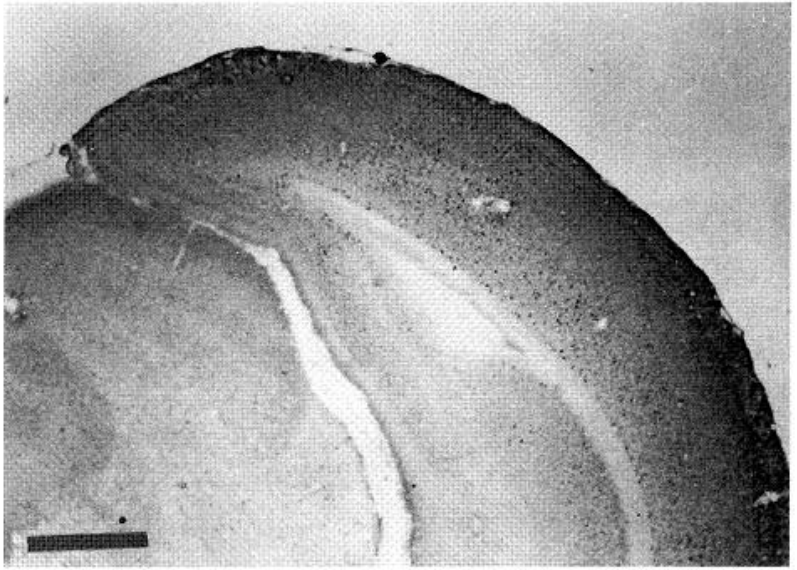

\section{Visual Cortex}
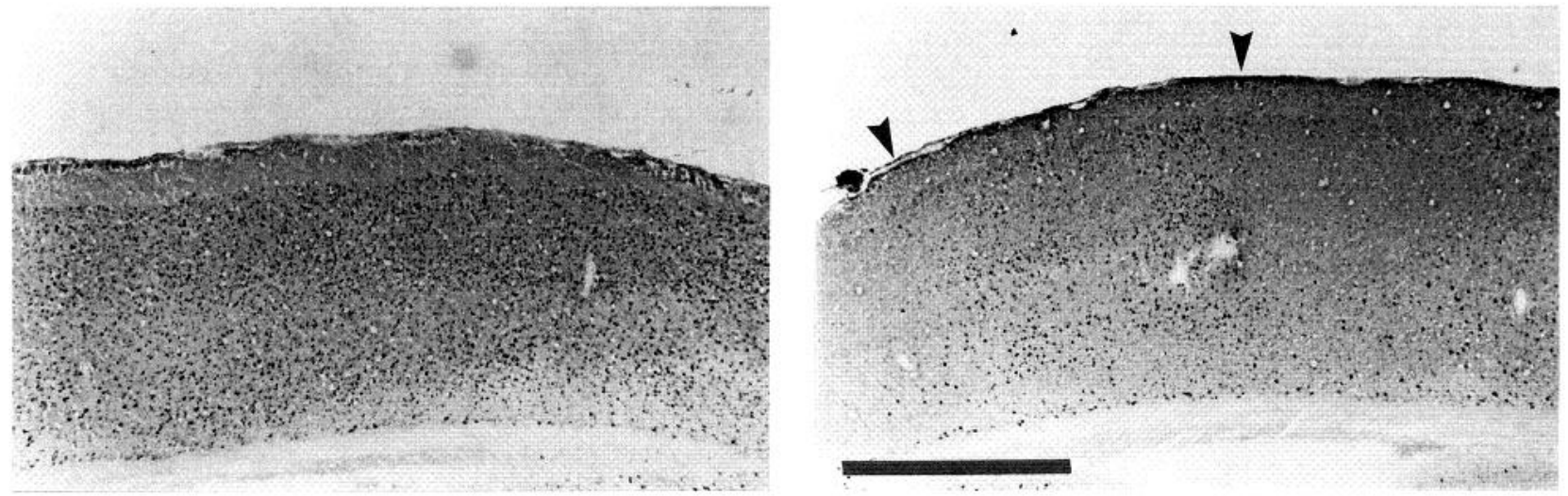

\section{Superior Colliculus}
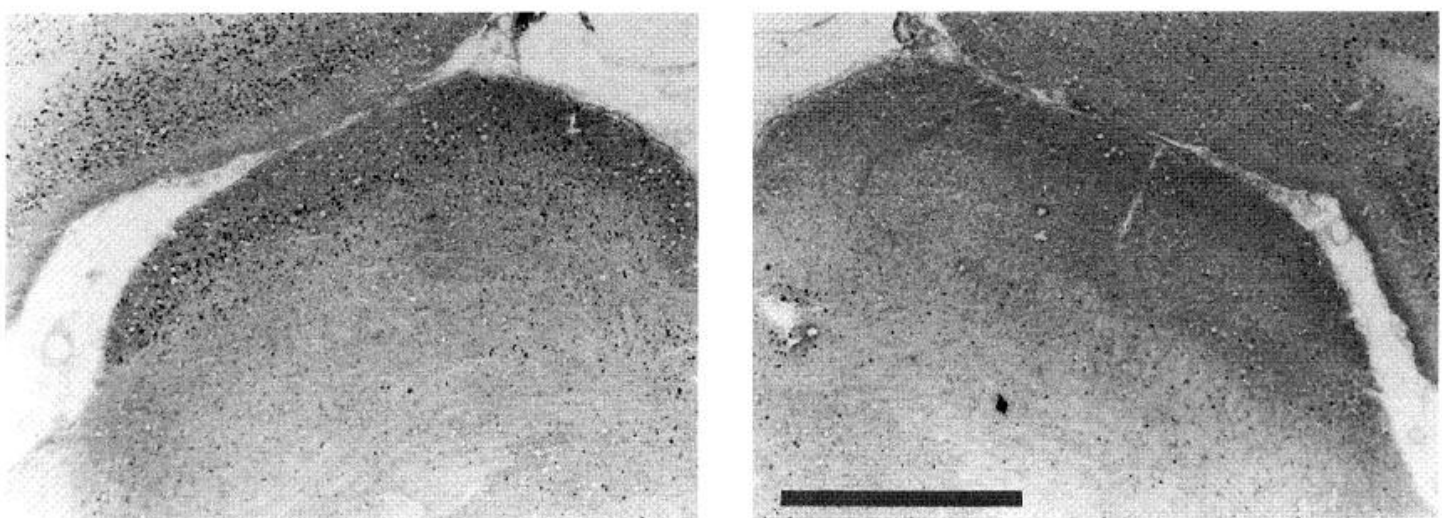

Figure 7. Immunocytochemical localization of c-Fos. Rats were monocularly enucleated, dark-reared for $6 \mathrm{~d}$, and exposed to light for $2 \mathrm{hr}$. The figure shows a composite of the c-Fos immunostaining in both visual cortex and superior colliculus. The side contralateral to the open eye showed immunostained neurons throughout visual cortex and along dorsal margin of the superior colliculus. On the ipsilateral side, staining was confined to a narrow zone that represented the binocular representation within visual cortex (region between arrowheads). The superior colliculus on this side was not stained. Scale bar, $1 \mathrm{~mm}$. 


\section{Zif 268}

\section{Contralateral}

\section{Ipsilateral}

\section{Visual Cortex}
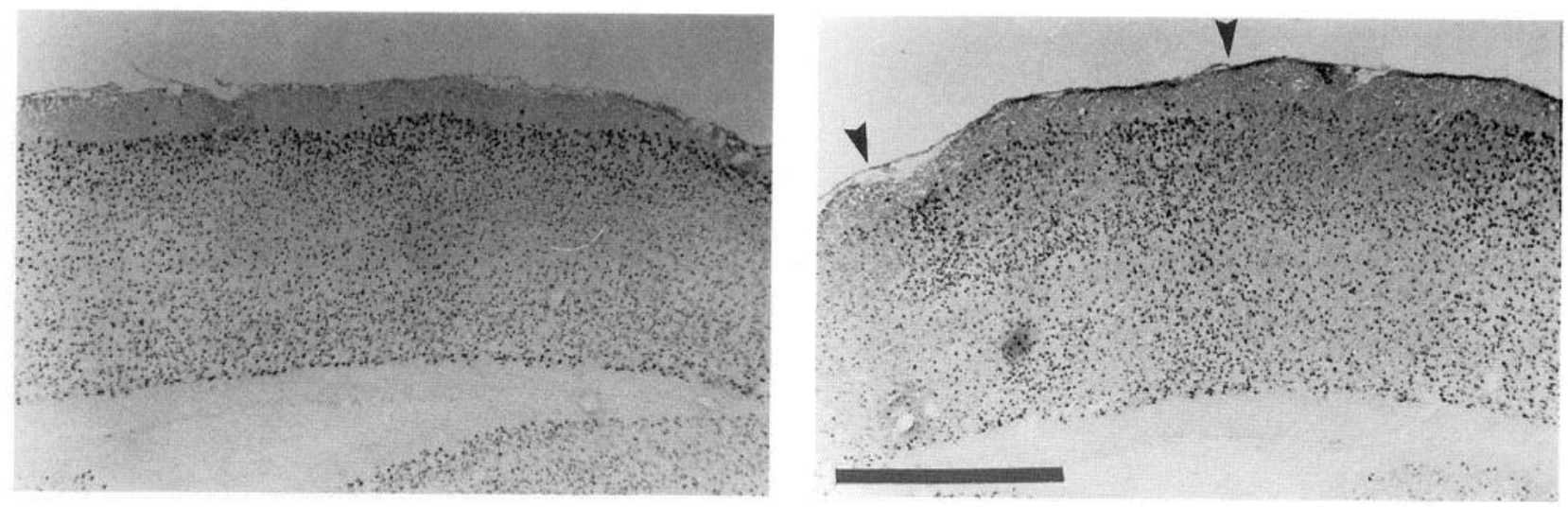

\section{Superior Colliculus}
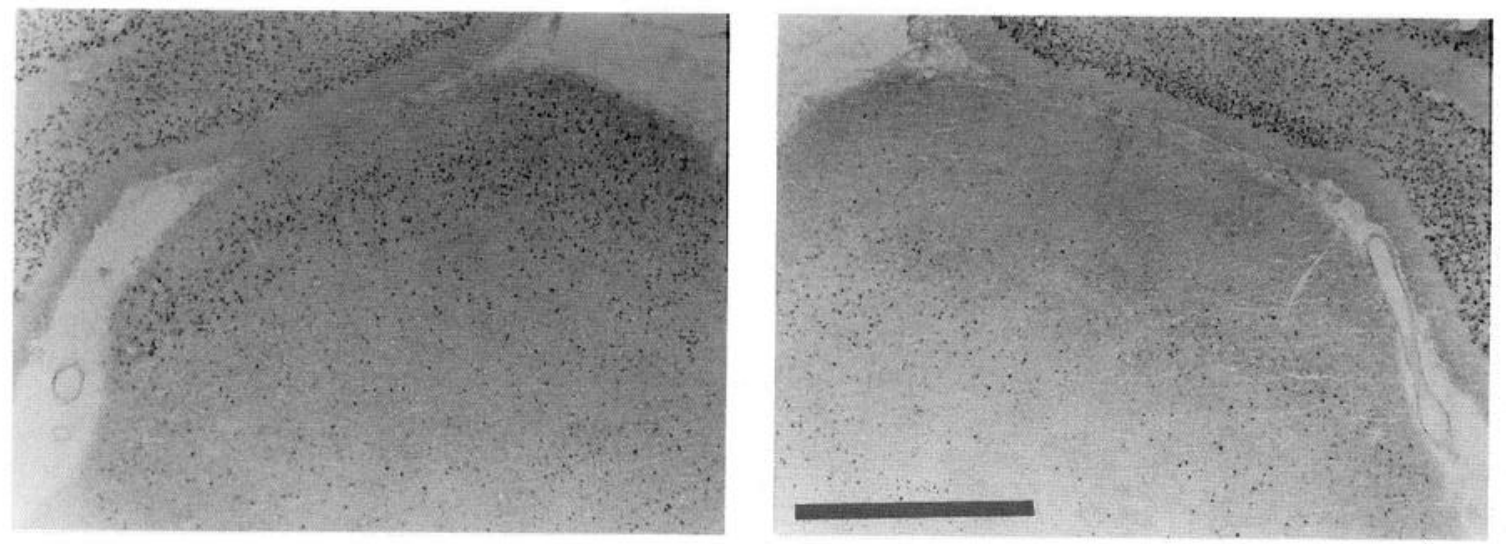

Figure 8. Immunocytochemical localization of Zif 268 . Rats were monocularly enucleated, dark-reared for $6 \mathrm{~d}$, and exposed to light for $2 \mathrm{hr}$. The figure shows a composite of the Zif 268 immunostaining in both visual cortex and superior colliculus. As with c-Fos immunostaining, the side contralateral to the open eye showed immunoreactive neurons throughout visual cortex and also along the dorsal margin of the superior colliculus. On the ipsilateral side, staining was confined to a narrow zone that represented the binocular representation (region between arrowheads) and flanked by reduced staining. The superior colliculus on this side was not stained. Scale bar, $1 \mathrm{~mm}$.

different roles in influencing gene expression (Chiu et al., 1989; Kobierski et al., 1991), our results invite further efforts at identifying them.

\section{REFERENCES}

Aronin N, Sagar SM, Sharp FR, Schwartz WJ (1990) Light regulates expression of a Fos-related protein in rat suprachiasmatic nuclei. Proc Natl Acad Sci USA 87:5959-5962.

Angel P, Karin M (1991) The role of Jun, Fos and the AP-1 complex in cell-proliferation and transformation. Biochim Biophys Acta 1072:129-157.

Beaver CJ, Mitchell DE, Robertson HA (1993) An immunohistochemical study of the rapid pattern of expression of c-Fos protein in the visual cortex of dark-reared kittens following initial exposure to light. J Comp Neurol 333:469-484.

Benson DL, Huntsman MM, Jones EG (1994) Activity dependent changes in GAD and preprotachykinin mRNAs in visual cortex of adult monkeys. Cereb Cortex 4:40-51.

Castren E, Zafra F, Thoenen H, Lindholm D (1992) Light regulates expression of brain-derived neurotrophic factor mRNA in rat visual cortex. Proc Natl Acad Sci USA 89:9444-9448.
Chaudhuri A, Cynader MS (1993) Activity-dependent expression of the transcription factor Zif 268 reveals ocular dominance columns in monkey striate cortex. Brain Res 605:349-353.

Chaudhuri A, Matsubara JA, Cynader MS (1995a) Neuronal activity in primate visual cortex assessed by immunostaining for the transcription factor Zif 268. Vis Neurosci 12:35-50.

Chaudhuri A, Larocque S, Nissanov J, Rioux L (1995b) Different temporal patterns of immediate-early gene RNA and protein expression allow multiple labeling strategies in visual cortex of monkey. Soc Neurosci Abstr 21:1752.

Chiu R, Angel P, Karin M (1989) Jun B differs in its biological properties from, and is negative regulator of c-Jun. Cell 59:979-986.

Davis RJ (1993) The mitogen-activated protein kinase signal transduction pathway. J Biol Chem 268:14553-14556.

Dragunow M, Faull R (1989) The use of c-fos as a metabolic marker in neuronal plasticity tracing. J Neurosci Methods 29:261-265.

Gass P, Herdegen T, Bravo R, Kiessling M (1993) Spatiotemporal induction of immediate early genes in the rat brain after limbic seizures: effects of NMDA receptor antagonist MK-801. Eur J Neurosci 5:933-943.

Hendry SHC, Kennedy MB (1986) Immunoreactivity for a calmodulindependent protein kinase is selectively increased in macaque striate 
cortex after monocular deprivation. Proc Natl Acad Sci USA 83:1536-1540.

Hope BT, Kelz MB, Duman RS, Nastler EJ (1993) Chronic electroconvulsive seizure (ECS) treatment results in expression of a long-lasting AP-1 complex in brain with altered composition and characteristics. J Neurosci 14:4318-4328.

Hunter T, Karin M (1992) The regulation of transcription by phosphorylation. Cell 70:375-387.

Kaczmarek L (1993a) L-Glutamate-driven gene expression in learning. Acta Neurobiol Exp 53:187-196.

Kaczmarek L (1993b) Molecular biology of vertebrate learning: is c-fos a new beginning? J Neurosci Res 34:377-381.

Kaczmarek L, Kaminska B (1989) Molecular biology of cell activation. Exp Cell Res 183:24-35.

Kaminska B, Filipkowski RK, Zurkowska G, Lason W, Przewlocki R, Kaczmarek L (1994) Dynamic changes in composition of the AP-1 transcription factor DNA binding activity in rat brain following kainate induced seizures and cell death. Eur J Neurosci 6:1558-1566.

Kaminska B, Kaczmarck L (1993) Robust induction of AP-1 transcription factor DNA binding activity in the hippocampus of aged rats. Neurosci Lett 153:189-191.

Kaminska B, Mosieniak G, Gierdalski M, Kossut M, Kaczmarek L (1995) Elevated AP-1 transcription factor DNA binding activity at the onset of functional plasticity during development of rat sensory cortical areas. Mol Brain Res 33:295-304.

Kasof GM, Mandelzys A, Maika SD, Hammer RE, Curran T, Morgan JI (1995) Kainic acid-induced neuronal death is associated with DNA damage and a unique immediate-early gene response in c-fos-lacZ transgenic rats. J Neurosci 15:4238-4249.

Kerppola TK, Curran T (1994) Maf and Nrl can bind to AP-1 sites and form heterodimers with Fos and Jun. Oncogene 9:675-84.

Kiessling M, Stumm G, Xie Y, Herdegen T, Aguzzi A, Bravo R, Gass P (1993) Differential transcription and translation of immediate early genes in the gerbil hippocampus after transient global ischemia. J Cereb Blood Flow Metab 13:914-924.

Kobierski LA, Chu H-M, Tan Y, Comb MJ (1991) cAMP-dependent regulation of proenkephalin by Jun D and Jun B: positive and negative effects of AP-1 proteins. Proc Natl Acad Sci USA 88:10222-10226.

Leah JD, Herdegen T, Murashov A, Dragunow M, Bravo R (1993) Expression of immediate early gene proteins following axotomy and inhibition of axonal transport in the rat central nervous system. Neuroscience 57:53-66.

Lukasiuk K, Kaczmarek L (1994) AP-1 and CRE DNA binding activities in rat brain following pentylenetetrazole induced seizures. Brain Res 643:227-233.

McCormack M, Rosen KM, Villa-Komaroff L, Mower GD (1992) Changes in immediate early gene expression during postnatal development of cat cortex and cerebellum. Mol Brain Res 12:215-223.
Merzenich MM, Sameshima K (1993) Cortical plasticity and memory. Curr Opin Neurobiol 3:187-196.

Morgan JI, Curran T (1991) Stimulus-transcription coupling in the nervous system: involvement of the inducible protooncogenes fos and jun. Annu Rev Neurosci 14:421-451.

Morgan JI, Curran T (1995) Immediate-early genes: ten years on. Trends Neurosci 18:66-67.

Mower GD (1994) Differences in the induction of Fos protein in cat visual cortex during and after the critical period. Mol Brain Res 21:47-54.

O'Leary DD, Ruff NL, Dyck RH (1994) Development, critical period plasticity, and adult reorganizations of mammalian somatosensory systems. Curr Opin Neurobiol 4:535-544.

Rosen KM, McCormack MA, Villa-Komaroff L, Mower GD (1992) Brief visual experience induces immediate early gene expression in the cat visual cortex. Proc Natl Acad Sci USA 89:5437-5441.

Rusak B, Robertson HA, Wisden W, Hunt SP (1990) Light pulses that shift rhythms induce gene expression in the suprachiasmatic nucleus. Science 248:1237-1240.

Ryseck RP, Bravo R (1991) c-JUN, JUN B, and JUN D differ in their binding affinitics to the AP-1 and CRE consensus sequences: effect of FOS proteins. Oncogene 6:533-542.

Sagar SM, Sharp FR (1990) Light induces a Fos-like nuclear antigen in retinal neurons. Mol Brain Res 7:17-21.

Sagar SM, Sharp FR, Curran T (1988) Expression of c-fos protein in brain: metabolic mapping at the cellular level. Science 240:328-331.

Sheng M, Greenberg ME (1990) The regulation of function of c-fos and other immediately early genes in the nervous system. Neuron 4:477-485.

Sonnenberg JL, Mitchelmore C, Macgregor-Leon PF, Hempstead J, Morgan JI, Curran T (1989) Glutamate receptor agonists increase the expression of Fos, Fra and AP-1 DNA binding activity in the mammalian brain. J Neurosci Res 24:72-80.

Worley P, Bhat RV, Baraban JM, Erickson CA, McNaughton BL, Barnes CA (1993) Thresholds for synaptic activation of transcription factors in hippocampus: correlation with long-term enhancement. J Neurosci 13:4776-4786.

Worley P, Christy BA, Nakabeppu Y, Bhat RV, Cole AJ, Baraban JM (1991) Constitutive expression of zif/268 in neocortex is regulated by synaptic activity. Proc Natl Acad Sci USA 88:5106-5110.

Worley P, Cole AJ, Murphy TH, Christy BA, Nakabeppu Y, Baraban JM (1990) Synaptic regulation of immediate-early genes in brain. Cold Spring Harbor Symp Quant Biol 50:213-223.

Zilles K, Wree A, Schleicher A, Divac I (1984) The monocular and binocular subfields of the rat's primary visual cortex: a quantitative morphological approach. J Comp Neurol 226:391-402. 